\title{
Distributed Drives Monitoring and Control: A Laboratory Setup
}

\author{
Mini Sreejeth, Parmod Kumar, and Madhusudan Singh \\ Department of Electrical Engineering, Delhi Technological University, Bawana Road, New Delhi 110042, India \\ Correspondence should be addressed to Mini Sreejeth; minisreejeth@dce.ac.in
}

Received 21 November 2012; Revised 24 December 2012; Accepted 30 December 2012

Academic Editor: Paolo Colantonio

Copyright (C) 2013 Mini Sreejeth et al. This is an open access article distributed under the Creative Commons Attribution License, which permits unrestricted use, distribution, and reproduction in any medium, provided the original work is properly cited.

\begin{abstract}
A laboratory setup of distributed drives system comprising a three-phase induction motor (IM) drive and a permanent magnet synchronous motor (PMSM) drive is modeled, designed, and developed for the monitoring and control of the individual drives. The integrated operation of IM and PMSM drives system has been analyzed under different operating conditions, and their performance has been monitored through supervisory control and data acquisition (SCADA) system. The necessary SCADA graphical user interface (GUI) has also been created for the display of drive parameters. The performances of IM and PMSM under parametric variations are predicted through sensitivity analysis. An integrated operation of the drives is demonstrated through experimental and simulation results.
\end{abstract}

\section{Introduction}

Monitoring and control of drives is a necessary prerequisite for quality control of a product as well as for energy conservation in automated process plants. Electrical energy is supplied to the motors through power electronic converter to get the desired torque/speed characteristics of the motors for motion control in industrial processes. This is achieved through modern motor drives, advance control algorithms, and intelligent devices such as programmable logic controller (PLC), digital signal processor (DSP), and microcontroller. This makes the operation of drives complex, sophisticated, and expensive [1]. Further, in production plant, the process is distributed at shop level based on functional requirements, which results in distribution of the various drives for different process operations. In distributed drives system, the processing tasks are physically distributed among the various drives, which requires placement of the necessary computing, with optimal volume of data, close to the process. Such system also provides fault tolerant and self-diagnostic capability and enhances the reliability of overall system. Thus, a distributed drives system has partially autonomous local computing devices with input, output, and storage capability, interconnected through a digital communication link coordinated by a supervisory control and data acquisition system. The distributed system has the advantages of local as well as centralized control. In such cases, the SCADA and programmable logic controller coordinate the local controllers through a communication link [2].

In the past few decades, limited literatures are available on distributed drives control using PLC. Applications of PLC have been reported for monitoring control system of an induction motor $[3,4]$. PLC has been also used as a power factor controller for power factor improvement and to keep the voltage to frequency ratio of a three-phase IM, constant under all control conditions [5]. Also, a vector-oriented control scheme, for the regulation of voltage and current of threephase pulse width modulation inverter, which uses a complex programmable logic device (CPLD) [6], has been reported. Remote control and operation of electric drive need a large amount of data to be acquired, processed, and presented by the SCADA system $[7,8]$. In this paper, distributed control for a three-phase IM drive and a three-phase PMSM drive is configured, designed, and developed for experimental work, and integrated control operation is demonstrated through experimental and simulation results. The application of adjustable speed drives (ASDs) for fans, pumps, blowers, and compressors do not require very precise speed control. Speed sensor in a drive adds cost and reduces the reliability of the drive. Therefore, for applications requiring moderate performance, sensorless drive is a better option, and, hence, sensorless vector control is used for IM control [9-14]. On the 
other hand, PMSMs are generally used for low-power servo applications where very precise position control is required. A PID controller is applied [15] to the position control, and a model reference adaptive control has been implemented for the PMSM [16]. As speed estimators and observers rely on the knowledge of motor parameters, they are inadequate for accurate position estimation. In the present work, a position feedback encoder is used for PMSM, and an indirect fieldoriented control is employed for its control [17-19].

A detailed study on distributed drives including design, development, and testing of prototype distributed drives is demonstrated. The monitoring and supervisory control of IM and PMSM drives, thereby validating the concept of distributed drives, is also described. Further, the developed experimental setup enables and facilitates imparting training and providing the facilities with hands of experimentation, research, and practical training. The necessary SCADA GUI has also been created for the display of drive parameters such as speed. The performances of IM and PMSM are predicted by sensitivity analysis.

\section{Control Algorithm}

Sensorless control for IM and indirect field-oriented control for the PMSM have been used in distributed control of the drives.

\subsection{Sensorless Control of Three-Phase IM Drive}

2.1.1. Flux Estimator. The direct and quadrature rotor flux components $\left(\psi_{d r}^{s}\right.$ and $\left.\psi_{q r}^{s}\right)$ are estimated from the IM terminal voltages $\left(v_{a}, v_{b}\right.$, and $\left.v_{c}\right)$, currents $\left(i_{a}, i_{b}\right.$, and $\left.i_{c}\right)$, stator resistance of the motor, $R_{s}$, the stator and rotor selfinductances $L_{s}$ and $L_{r}$, respectively, and their mutual inductance $L_{m}$, which are described in (1) to (3); [20], consider

$$
\begin{aligned}
& \psi_{d s}^{s}=\int\left(v_{d s}^{s}-R_{s} i_{d s}^{s}\right) d t, \\
& \psi_{q s}^{s}=\int\left(v_{q s}^{s}-R_{s} i_{q s}^{s}\right) d t,
\end{aligned}
$$

where

$$
\begin{gathered}
v_{q s}^{s}=\frac{2}{3} v_{a}-\frac{1}{3} v_{b}-\frac{1}{3} v_{c}, \\
v_{d s}^{s}=-\frac{1}{\sqrt{3}} v_{b}+\frac{1}{\sqrt{3}} v_{c}, \\
i_{q s}^{s}=\frac{2}{3} i_{a}-\frac{1}{3} i_{b}-\frac{1}{3} i_{c}, \\
i_{d s}^{s}=-\frac{1}{\sqrt{3}} i_{b}+\frac{1}{\sqrt{3}} i_{c}, \\
\psi_{d r}^{s}=\frac{L_{r}}{L_{m}}\left(\psi_{d s}^{s}-\sigma L_{s} i_{d s}^{s}\right), \\
\psi_{q r}^{s}=\frac{L_{r}}{L_{m}}\left(\psi_{q s}^{s}-\sigma L_{s} i_{q s}^{s}\right),
\end{gathered}
$$

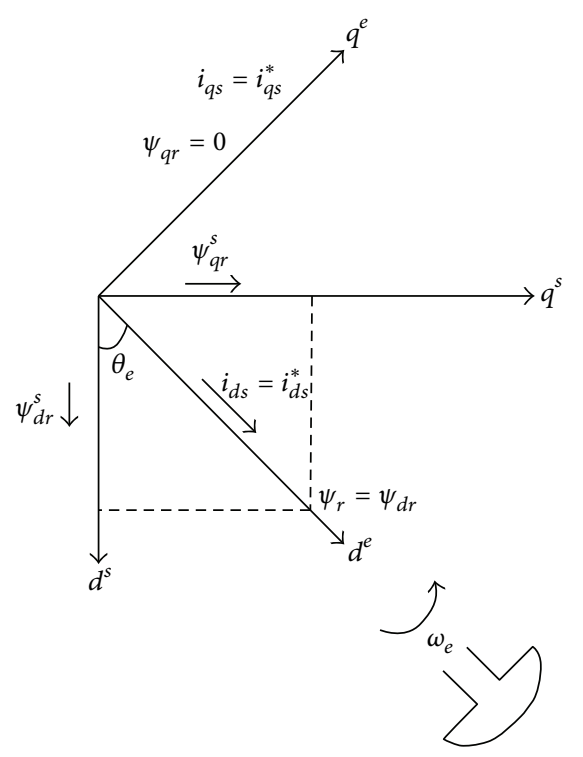

FIGURE 1: Phasors showing rotor flux orientation.

where

$$
\sigma=1-\frac{L_{m}^{2}}{L_{r} L_{s}}
$$

and $i_{d s}^{s}, i_{q s}^{s}, \psi_{d s}^{s}$, and $\psi_{q s}^{s}$ are stator direct and quadrature axis currents and fluxes, respectively.

Also,

$$
\psi_{r}=\sqrt{\left(\psi_{q r}^{s}\right)^{2}+\left(\psi_{d r}^{s}\right)^{2}} .
$$

The correct alignment of current, $i_{d s}$, in the direction of flux, $\psi_{r}$, and the current, $i_{q s}$, perpendicular to it are needful requirements in vector control. This alignment is depicted in Figure 1 using rotor flux vectors $\psi_{d r}^{s}$ and $\psi_{q r}^{s}$, where $d^{e}$ $q^{e}$ frame is rotating at synchronous speed with respect to stationary frame $d^{s}-q^{s}$, and at any instance, the angular position of $d^{e}$ axis with respect to the $d^{s}$ axis is $\theta_{e}$, where

$$
\begin{gathered}
\theta_{e}=\omega_{e} t, \quad \cos \theta_{e}=\frac{\psi_{d r}^{s}}{\psi_{r}}, \\
\sin \theta_{e}=\frac{\psi_{q r}^{s}}{\psi_{r}} .
\end{gathered}
$$

2.1.2. Speed Estimator. The speed is estimated by using the data of the rotor flux vector $\left(\psi_{r}\right)$, obtained in a flux estimator as follows. ten as

The rotor circuit equations [20] of $d^{s}-q^{s}$ frame are writ-

$$
\begin{aligned}
& \frac{d \psi_{d r}^{s}}{d t}+R_{r} i_{d r}^{s}+\omega_{r} \psi_{q r}^{s}=0, \\
& \frac{d \psi_{q r}^{s}}{d t}+R_{r} i_{q r}^{s}-\omega_{r} \psi_{d r}^{s}=0 .
\end{aligned}
$$


Adding terms $\left(L_{m} R_{r} / L_{r}\right) i_{d s}^{s}$ and $\left(L_{m} R_{r} / L_{r}\right) i_{q s}^{s}$, respectively, on both sides of the previous equation, we get

$$
\begin{gathered}
\frac{d \psi_{d r}^{s}}{d t}+\frac{R_{r}}{L_{r}}\left(L_{m} i_{d s}^{s}+L_{r} i_{d r}^{s}\right)+\omega_{r} \psi_{q r}^{s}=\left(\frac{L_{m} R_{r}}{L_{r}}\right) i_{d s}^{s}, \\
\frac{d \psi_{q r}^{s}}{d t}+\frac{R_{r}}{L_{r}}\left(L_{m} i_{q s}^{s}+L_{r} i_{q r}^{s}\right)-\omega_{r} \psi_{d r}^{s}=\left(\frac{L_{m} R_{r}}{L_{r}}\right) i_{q s}^{s}, \\
\frac{d \psi_{d r}^{s}}{d t}=\frac{L_{m}}{\tau_{r}} i_{d s}^{s}-\omega_{r} \psi_{q r}^{s}-\frac{1}{\tau_{r}} \psi_{d r}^{s}, \\
\frac{d \psi_{q r}^{s}}{d t}=\frac{L_{m}}{\tau_{r}} i_{q s}^{s}+\omega_{r} \psi_{d r}^{s}-\frac{1}{\tau_{r}} \psi_{q r}^{s},
\end{gathered}
$$

where

$$
\begin{aligned}
& L_{m} i_{d s}^{s}+L_{r} i_{d r}^{s}=\psi_{d r}^{s}, \\
& L_{m} i_{q s}^{s}+L_{r} i_{q r}^{s}=\psi_{q r}^{s},
\end{aligned}
$$

and $\tau_{r}$ (i.e., $L_{r} / R_{r}$ ) is the rotor time response. Also, from (5),

$$
\theta_{e}=\tan ^{-1} \frac{\psi_{q r}^{s}}{\psi_{d r}^{s}}
$$

Differentiating the aforementioned, we get

$$
\frac{d \theta_{e}}{d t}=\frac{\psi_{d r}^{s} \psi_{q r}^{\prime^{s}}-\psi_{q r}^{s} \psi_{d r}^{\prime^{s}}}{\psi_{r}^{2}}
$$

Combining (7), (8), and (13) and simplifying, one yields

$$
\begin{gathered}
\omega_{r}=\frac{d \theta_{e}}{d t}-\frac{L_{m}}{\tau_{r}}\left[\frac{\psi_{d r}^{s} i_{q s}^{s}-\psi_{q r}^{s} i_{d s}^{s}}{\psi_{r}^{2}}\right], \\
\omega_{r}=\frac{1}{\psi_{r}^{2}}\left(\left[\psi_{d r}^{s} \psi_{q r}^{\prime^{s}}-\psi_{q r}^{s} \psi_{d r}^{\prime^{s}}\right]-\frac{L_{m}}{\tau_{r}}\left[\psi_{d r}^{s} i_{q s}^{s}-\psi_{q r}^{s} i_{d s}^{s}\right]\right),
\end{gathered}
$$

where $\psi_{q r}^{\prime^{s}}$ and $\psi_{d r}^{\prime^{s}}$ are first derivatives of $\psi_{q r}^{s}$ and $\psi_{d r}^{s}$, respectively.

The torque component of current $i_{q s}^{*}$ and the flux component of current $i_{d s}^{*}$ are evaluated from the speed control loop and the flux control loop, respectively, as follows:

$$
\begin{aligned}
& i_{q s}^{*}=\left(\omega_{r}-\omega_{r}^{*}\right) G_{1}, \\
& i_{d s}^{*}=\left(\Psi_{r}-\Psi_{r}^{*}\right) G_{2},
\end{aligned}
$$

where $\omega_{r}^{*}$ and $\psi_{r}^{*}$ are the reference speed and flux; $G_{1}$ and $G_{2}$ are the gain of speed loop and flux loop; $\psi_{r}$ and $\omega_{r}$ are computed using the flux and speed estimators, respectively, as explained earlier.

The principal vector control parameters, $i_{d s}^{*}$ and $i_{q s}^{*}$, which are DC values in synchronously rotating frame, are converted to stationary frame with the help of unit vectors $(\sin \theta$ and $\cos \theta$ ) generated from flux vectors $\psi_{d r}^{s}$ and $\psi_{q r}^{s}$ as given by (5).
The resulting stationary frame signals are then converted to phase current commands for the inverter [20]. The torque is estimated using (16) as

$$
T_{e}=\frac{3}{2}\left(\frac{P}{2}\right) \frac{L_{m}}{L_{r}}\left(\psi_{d r}^{s} i_{q s}^{s}-\psi_{q r}^{s} i_{d s}^{s}\right) .
$$

The block diagram of the sensorless vector control for the IM drive is shown in Figure 2.

2.2. Control Scheme for Three-Phase PMSM Drive. The rotor of PMSM is made up of permanent magnet of Neodymiumiron-boron, which offers high energy density. Based on the assumptions that (i) the rotor copper losses are negligible, (ii) there is no saturation, (iii) there are no field current dynamics, and (iv) no cage windings are on the rotor, the stator $d-q$ equations of the PMSM in the rotor reference frame are as follows $[17,21]$ :

$$
\begin{aligned}
& v_{q s}=R_{s} i_{q s}+\frac{d}{d t} \lambda_{q s}+\omega_{s} \lambda_{d s}, \\
& v_{d s}=R_{s} i_{d s}+\frac{d}{d t} \lambda_{d s}-\omega_{s} \lambda_{q s},
\end{aligned}
$$

where

$$
\begin{gathered}
\lambda_{q s}=L_{q s} i_{q s}, \\
\lambda_{d s}=L_{d s} i_{d s}+\lambda_{f} .
\end{gathered}
$$

$v_{d s}$ and $v_{q s}$ are the $d, q$ axis voltages, $i_{d s}$ and $i_{q s}$ are the $d, q$ axis stator currents, $L_{d s}$ and $L_{q s}$ are the $d, q$ axis inductance, $\lambda_{d s}$ and $\lambda_{q s}$ are the $d, q$ axis stator flux linkages, $\lambda_{f}$ is the flux linkage due to the rotor magnets linking the stator, while $R_{s}$ and $\omega_{s}$ are the stator resistance and inverter frequency, respectively. The inverter frequency $\omega_{s}$ is related to the rotor speed $\omega_{r}$ as follows:

$$
\omega_{s}=\frac{P}{2} \omega_{r}
$$

where $P$ is the number of poles, and the electromagnetic torque $T_{e}$ is

$$
T_{e}=\frac{3}{2}\left(\frac{P}{2}\right)\left[\lambda_{f} i_{q s}+\left(L_{d s}-L_{q s}\right) i_{d s} i_{q s}\right] .
$$

This torque, $T_{e}$, encounters load torque, moment of inertia of drive, and its damping constant. Thus, the equation for the motion is given by

$$
T_{e}=T_{L}+B \omega_{r}+J \frac{d}{d t} \omega_{r},
$$

where $T_{L}$ is the load torque, $J$ moment of inertia, and $B$ damping coefficient.

Figure 3 shows the typical block diagram of a PMSM drive. The system consists of a PMSM, speed/position feedback, an inverter, and a controller (constant torque and flux weakening operation, generation of reference currents, and PI controller). The error between the commanded and actual 


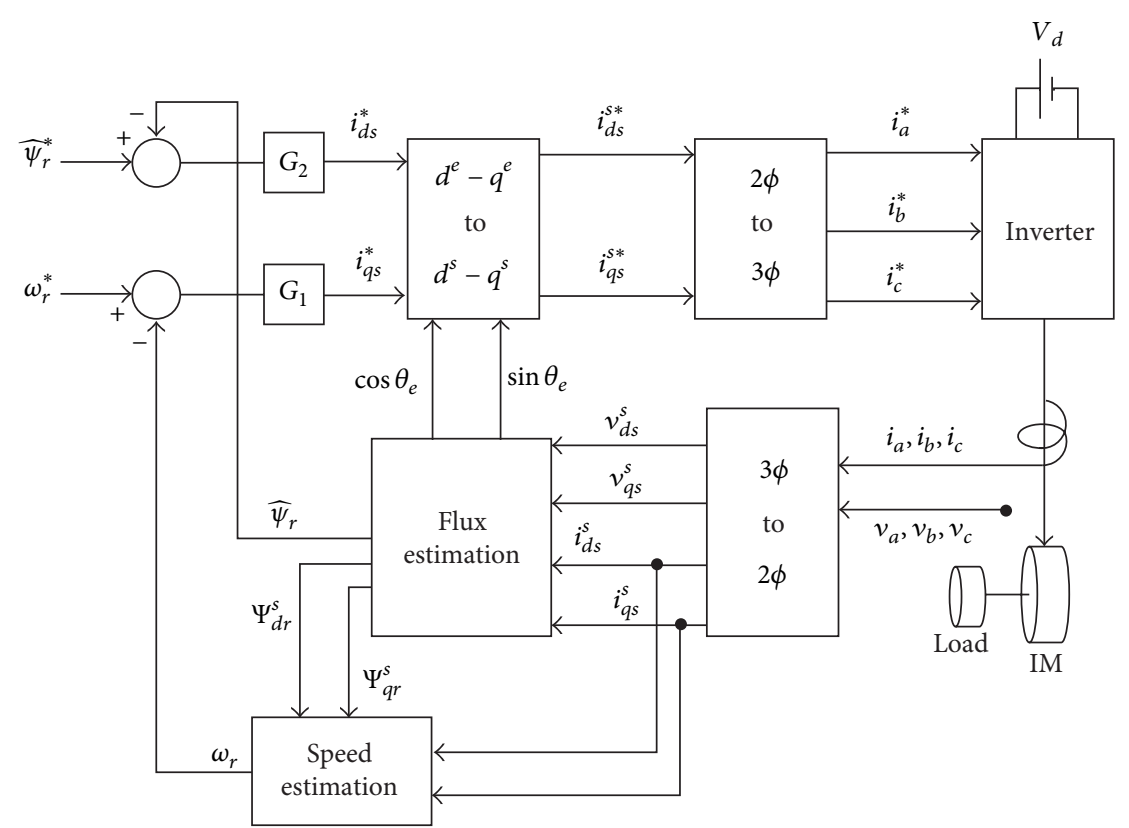

FIGURE 2: Block diagram of sensor less vector control for three-phase IM drive.

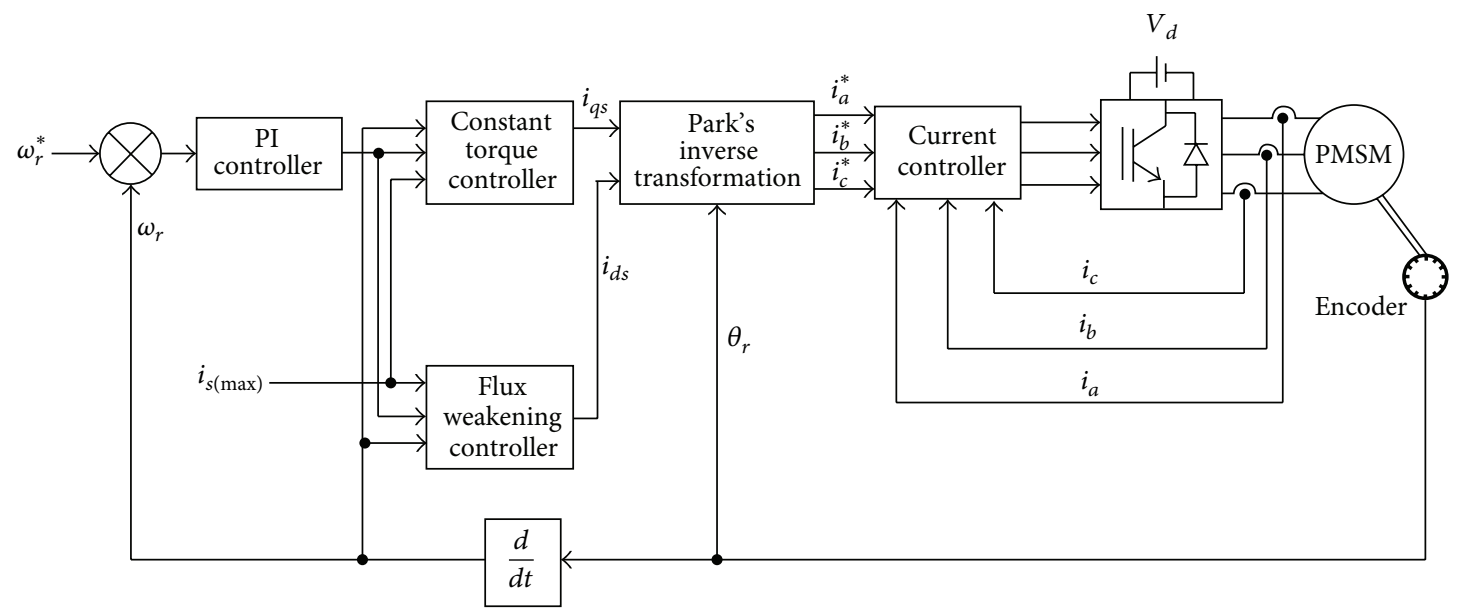

FIgURE 3: Block diagram of three-phase PMSM drive.

speed is operated upon by the PI controller to generate the reference torque.

The ratio of torque reference and motor torque constant is used during constant torque operation to compute the reference quadrature axis current, $i_{q s}$. For operation up to rated speed, the direct axis current is made equal to zero. From these $d-q$ axes currents and the rotor position/speed feedback, the reference stator phase currents are obtained using Park's inverse transformation as given in (22)

$$
\left[\begin{array}{l}
i_{a} \\
i_{b} \\
i_{c}
\end{array}\right]=\left[\begin{array}{ccc}
\cos \theta_{r} & \sin \theta_{r} & 1 \\
\cos \left(\theta_{r}-\frac{2 \pi}{3}\right) & \sin \left(\theta_{r}-\frac{2 \pi}{3}\right) & 1 \\
\cos \left(\theta_{r}+\frac{2 \pi}{3}\right) & \sin \left(\theta_{r}+\frac{2 \pi}{3}\right) & 1
\end{array}\right]\left[\begin{array}{c}
i_{q s} \\
i_{d s} \\
i_{0 s}
\end{array}\right],
$$

where $i_{0 s}$ is the zero sequence current, which is zero for a balanced system.
The hysteresis PWM current controller attempts to force the actual motor currents to reference current values using stator current feedback. The error between these currents is used to switch the PWM inverter. The output of the PWM is supplied to the stator of the PMSM, which yields the commanded speed. The position feedback is obtained by an optical encoder mounted on the machine shaft.

In order to operate the drive in the flux weakening mode, it is essential to find the maximum speed. The maximum operating speed with zero torque can be obtained from the steady state stator voltage equations. The flux weakening controller computes the demagnetizing component of stator current, $i_{d s}$, satisfying the maximum current and voltage limits. For this direct axis current and the rated stator current, the quadrature axis current can be obtained from (23)

$$
I_{s}=\sqrt{i_{d s}^{2}+i_{q s}^{2}} \text {. }
$$




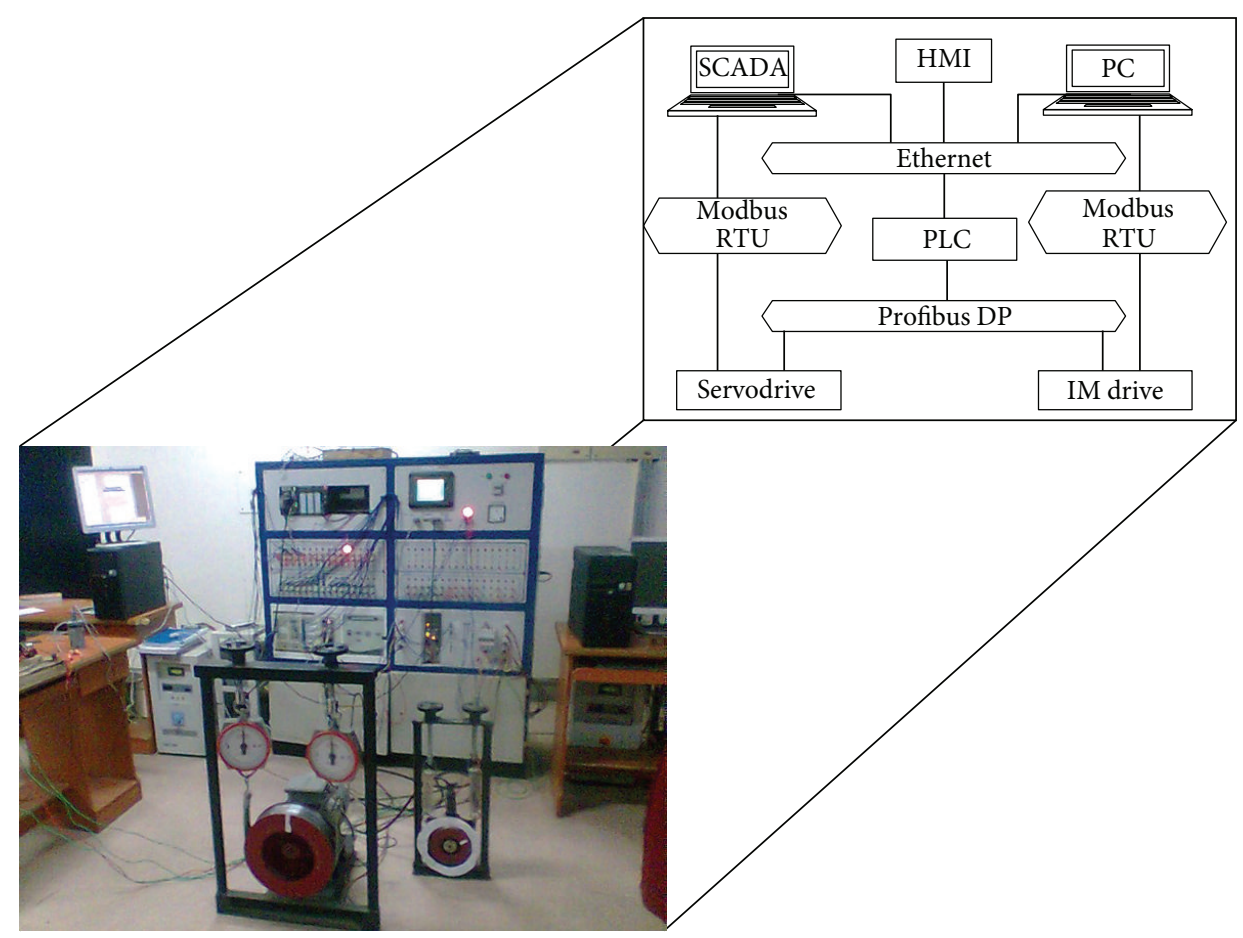

FIGURE 4: Schematic layout of distributed drives laboratory setup.

These $d-q$ axes currents and the rotor position/speed can be utilized to obtain the commanded speed.

\section{Sensitivity Analysis of IM and PMSM}

Sensitivity analysis is used by designers of machines for the prediction of the effect of parameter of interest on the performance variables of the motor. In the present study, sensitivity values of the performance variables like power input, power output, efficiency, power factor, stator current, starting current, magnetizing current, developed torque, and starting torque, with respect to the equivalent circuit parameters, are obtained for the IM. The sensitivity is computed by (24), as sensitivity of a variable $N$ with respect to a parameter $\alpha$ can be represented as

$$
S_{\alpha}^{N}=100 \cdot \frac{\left(N_{c}-N_{n}\right)}{N_{n}},
$$

where $N_{n}$ is the performance variable with nominal parameters, and $N_{c}$ is the value of the performance variable when the value of the parameter $\alpha$ is increased by defined deviation value. A similar analysis is also carried out for PMSM.

\section{Laboratory Setup of the Distributed Drives System}

To analyse the utility of distributed drive system, a laboratory setup has been designed and developed for research and development activities. Figure 4 shows laboratory setup which incorporates industry standard networking. It has an IEEE 802.3 complaint Ethernet data highway and is currently supporting a network of two-operator consoles, a PLC, and two drives (IM drive and PMSM drive) all connected in star topology. The PLC (GE Fanuc 90-30) coordinates the operation of these drives. The PLC passes real-time data to the operator console via Ethernet interface using customized software, namely, VersaMotion, for PMSM drive and DCT software for the IM drive. The input/output (I/O) units of PLC and drives communicate using Profibus-DP [22, 23]. The communication between individual drives and PCs, SCADA, is through Modbus protocol.

4.1. PLC in Distributed Drive System. The PLC used in the laboratory setup consists of several modules, namely, Power Supply, CPU, Digital Input, Digital Output, and Network Modules. The digital input module is a $0-30 \mathrm{~V} \mathrm{DC}, 7 \mathrm{~mA}$ with positive/negative logic and 16 input points. This module is used to read ON/OFF position of different contacts used to control the drives. There are two output modules with 32 points operating at $24 \mathrm{~V} \mathrm{DC}$, which are used to output the status of the individual drive, alarm signal, and so forth based on the decision made by the control strategy that is written as ladder logic program in the PLC. The power supply of PLC is capable of supporting 100-240 V AC or $125 \mathrm{~V}$ DC. The CPU has a user logic memory of 240 Kbytes. The communication module includes Profibus module operating at baud rate of $1.5 \mathrm{Mbps}$ with a power requirement of $5 \mathrm{~V}$ DC. Proficy Machine Edition 5.9 provides software utilities for PLC programming. The PLC is programmed in ladder diagrams, and program is downloaded in the PLC from a personal computer through RS 232C serial interface. A ladder diagram consists of graphic symbols like contacts, coils, timers, counters, and so forth which are laid out in networks 


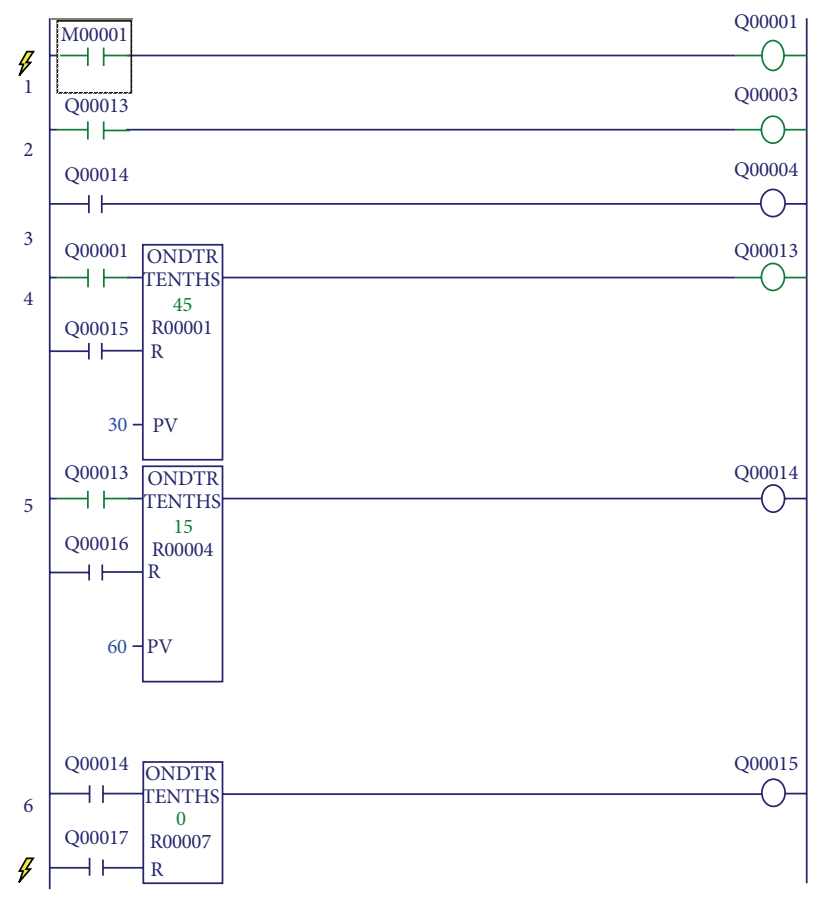

(a)

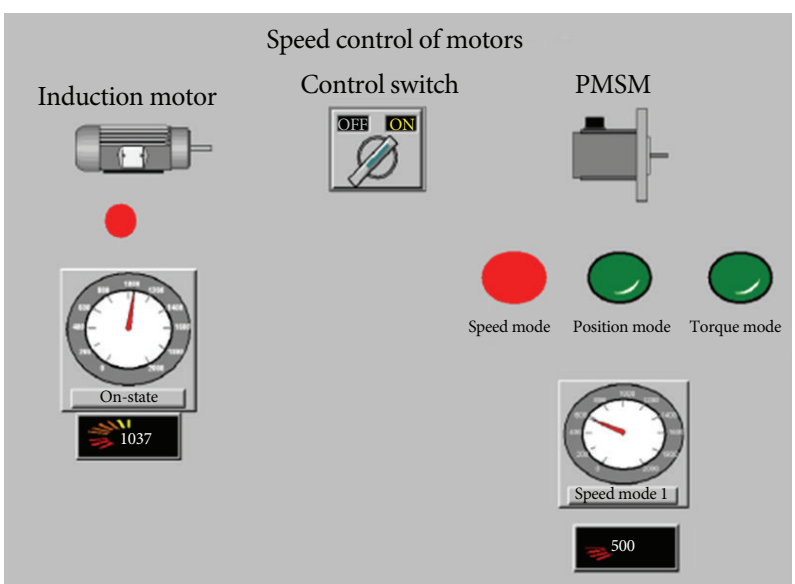

(b)

FIGURE 5: (a) Ladder logic for integrated operation of IM and PMSM drives. (b) SCADA GUI developed for the speed control of the distributed drives.

similar to a rung of a relay logic diagram. The PLC stores the inputs (ON/OFF status of coils), execute, the user program cyclically, and finally writes the outputs (energizing a coil for actual opening/closing of contacts) to the output status table. This read-execute-write cycle is called a scan cycle. The ladder logic diagram for the integrated operation of the IM and PMSM drives is shown in Figure 5(a).

4.2. SCADA. For the remote monitoring and control of the drives, GE Fanuc SCADA Cimplicity 7.5 software is used. The SCADA software is loaded on the server PC which provides supervision in the form of graphical animation and data trends of the processes on the window of PC or screen of HMI. The Cimplicity project wizard window is used to configure various communication ports and the controller type and also to create new points corresponding to addresses used in the controller. This graphical interactive window is used to animate the drive system. At present, controls like start, stop, speed control, and so forth are developed on the software window to control the drives remotely. Each drive can be controlled locally at the field level, through the PLC, or through the SCADA interface. The SCADA GUI developed for the speed control of the distributed drives is shown in Figure 5(b). The control algorithm has been implemented and tested for a three-phase squirrel cage induction motor and three-phase PMSM drive. The technical specifications for these drives are presented in Tables 1 and 2.

\section{Results and Discussions}

A three-phase sensorless induction drive and a three-phase PMSM drive are configured in the SCADA system. The

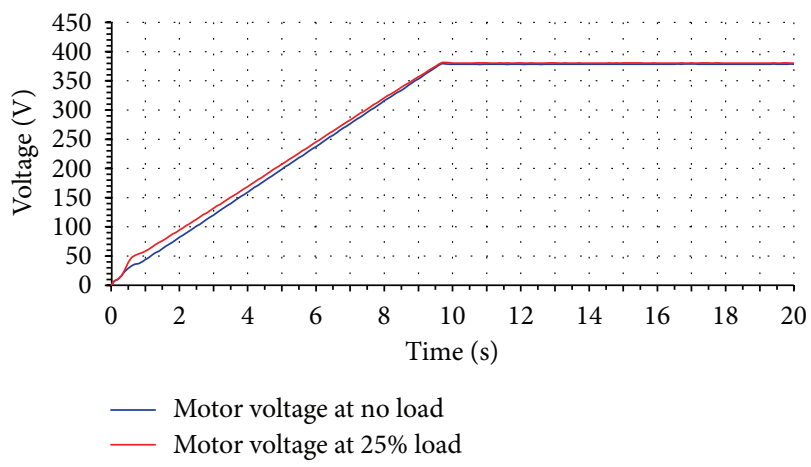

FIGURE 6: Voltage variation of IM drive during starting at different loads and $1440 \mathrm{rpm}$ speed.

operation and performance characteristics of the drives are monitored and studied under varying torque and speed conditions. Simulation results are also described. In order to study the effect of parametric variation on the motor performance variable, sensitivity analysis is carried out for both IM and PMSM with respect to their respective equivalent circuits.

5.1. Performance of Three-Phase IM Drive under Different Load Conditions. Figure 6 to Figure 11 show the variation of various parameters of sensorless control induction motor drive during starting at no load and $25 \%$ load conditions. Figures 6 and 7 show the variation of voltage and frequency. Both the voltage and frequency increase linearly till they attain a value of $385 \mathrm{~V}$ and $48 \mathrm{~Hz}$, respectively, at rated speed 
TABLE 1: Technical specifications of three-phase induction motor.

\begin{tabular}{lc}
\hline Connection type & $\Delta$ \\
\hline Input voltage & $415 \mathrm{~V} \pm 10 \%$ \\
Input current & $7 \mathrm{~A}$ \\
Rated power & $3.7 \mathrm{~kW}$ \\
Input frequency & $50 \mathrm{~Hz}$ \\
Pole number & 4 \\
Rated speed & $1440 \mathrm{rpm}$ \\
\hline
\end{tabular}

TABle 2: Technical specifications of three-phase PMSM.

\begin{tabular}{lc}
\hline Parameter & Value \\
\hline Rated output & $1.0 \mathrm{~kW}$ \\
Rated torque & $3.18 \mathrm{Nm}$ \\
Motor voltage & $110 \mathrm{~V}$ \\
Rated current & $7.3 \mathrm{~A}$ \\
Maximum current & $21.9 \mathrm{~A}$ \\
Encoder position feedback & $2500 \mathrm{ppr}$ \\
Peak torque & $9.54 \mathrm{Nm}$ \\
Rated speed & $3000 \mathrm{rpm}$ \\
Moment of inertia & $0.000265 \mathrm{~kg} \cdot \mathrm{m}^{2}$ \\
Armature resistance & $0.2 \Omega$ \\
Armature inductance & $2 \mathrm{mH}$ \\
\hline
\end{tabular}

under no load starting condition. While the machine is started with a load of $25 \%$, the variations in voltage and frequency are almost similar to that of the previous case.

Figure 8 shows the variation of current during starting under no load and $25 \%$ load conditions. The starting current was $4.38 \mathrm{~A}$ during starting which is settled down to a steady state value of $3.1 \mathrm{~A}$ in $2 \mathrm{~s}$ under no load case. While with $25 \%$ load, the starting current was $5.7 \mathrm{~A}$ which is settled down to steady state value of $3.25 \mathrm{~A}$ in about $10 \mathrm{~s}$.

Figure 9 shows the variation of torque during starting with no load and 25\% load. At no load starting, it is observed that the negative peak torque value is $5.9 \mathrm{Nm}$ at the first instance, and then it reaches a positive peak value of $10.3 \mathrm{Nm}$ and finally settles down to a steady state value of $0.7 \mathrm{Nm}$ in about 10 s. While with $25 \%$ load starting, the negative peak torque value at the first instance is $6 \mathrm{Nm}$, and the positive peak value is $20.1 \mathrm{Nm}$ which finally settles down to a steady value of $4.5 \mathrm{Nm}$ in $12 \mathrm{~s}$. Figure 10 shows the power variation at starting with no load and $25 \%$ load. The power drawn during transient period is $0.18 \mathrm{~kW}$, which decreases to a value of $0.1 \mathrm{~kW}$, then it increases linearly to a value of $0.3 \mathrm{~kW}$ and finally settles down to a value of $0.14 \mathrm{~kW}$ in $11 \mathrm{~s}$. When the machine is started with $25 \%$ load, the initial power drawn is $0.42 \mathrm{~kW}$, which then increases to a value of $1.3 \mathrm{~kW}$ and finally settles down to a value of $0.8 \mathrm{~kW}$ in $13 \mathrm{~s}$.

Figure 11 shows the speed response of IM during starting at no load and $25 \%$ load. It is observed that the motor reaches its rated speed that is, $1440 \mathrm{rpm}$ in about $9 \mathrm{~s}$ under no load starting and in about $10 \mathrm{~s}$ under $25 \%$ load at starting. Figure 12 shows simulated dynamic performance of IM drive under no

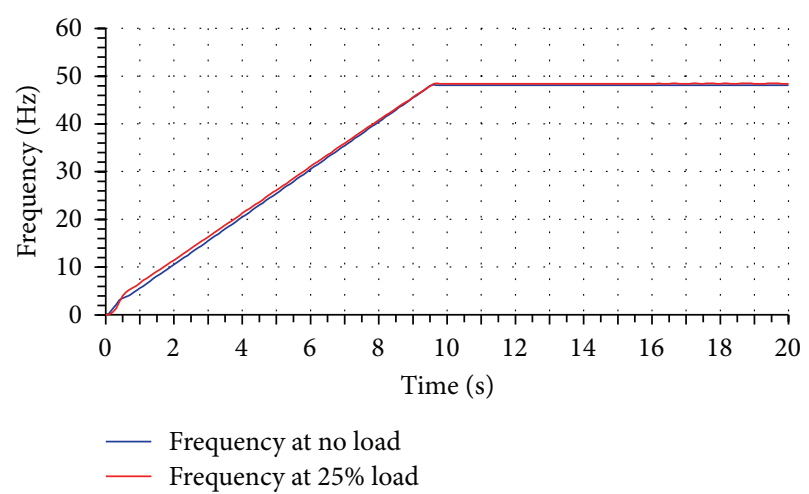

FIgURE 7: Frequency variation of IM drive during starting at different loads and $1440 \mathrm{rpm}$ speed.

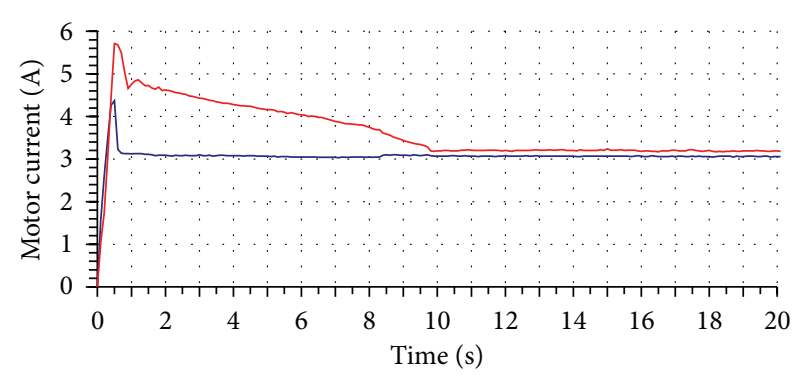

- Current at no load (A)

- Current at $25 \%$ load (A)

FIGURE 8: Current variation of IM drive during starting at different loads and $1440 \mathrm{rpm}$ speed.

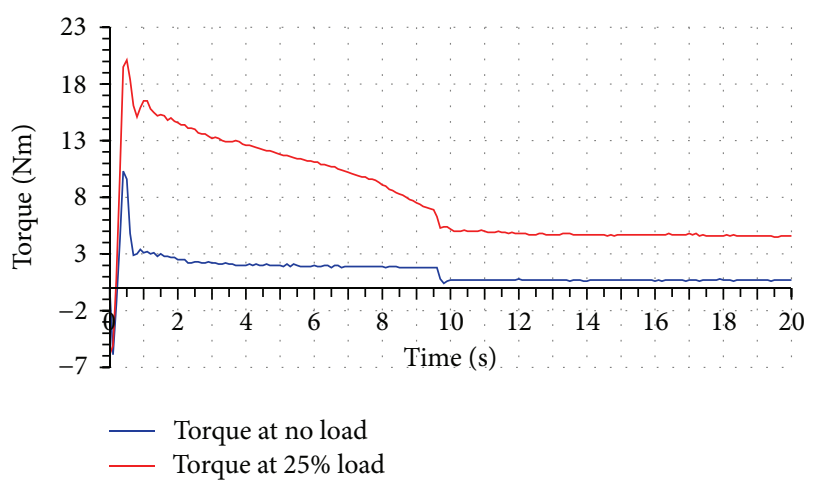

FIGURE 9: Torque variation of IM drive during starting at different loads and $1440 \mathrm{rpm}$ speed.

load and at rated speed of $1440 \mathrm{rpm}$. The motor attains the desired speed of $1440 \mathrm{rpm}$ in about $5.5 \mathrm{~s}$.

\subsection{Starting Performance of Three-Phase PMSM Drive under} No Load Condition. Figure 13 shows the dynamic performance of PMSM under no load with a reference speed of $3000 \mathrm{rpm}$. The motor attains the set synchronous speed of $3000 \mathrm{rpm}$ in about $300 \mathrm{~ms}$. Figure 14 shows simulated dynamic performance of PMSM at no load with a reference 


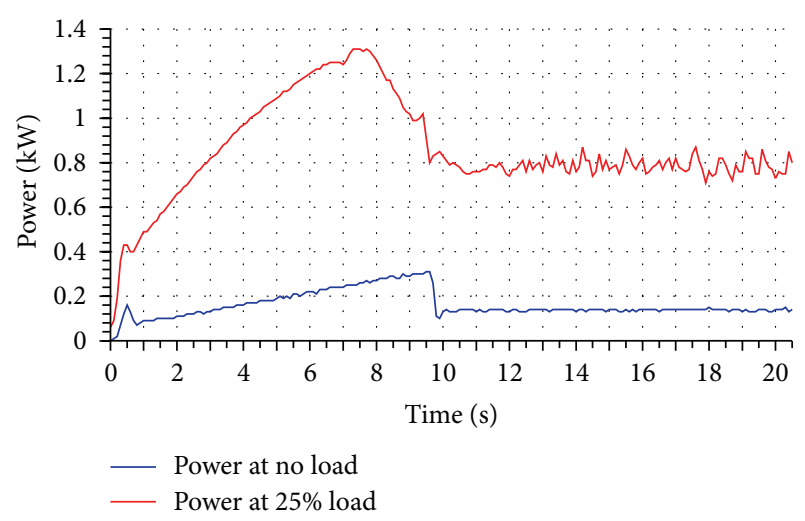

FIGURE 10: Power variation of IM drive during starting at different loads and $1440 \mathrm{rpm}$ speed.

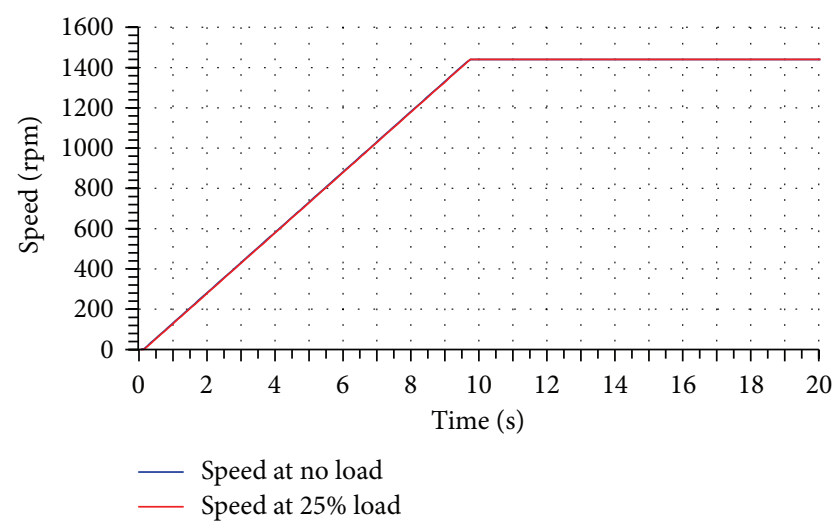

FIGURE 11: Speed variation of IM drive during starting at different loads and $1440 \mathrm{rpm}$ speed.

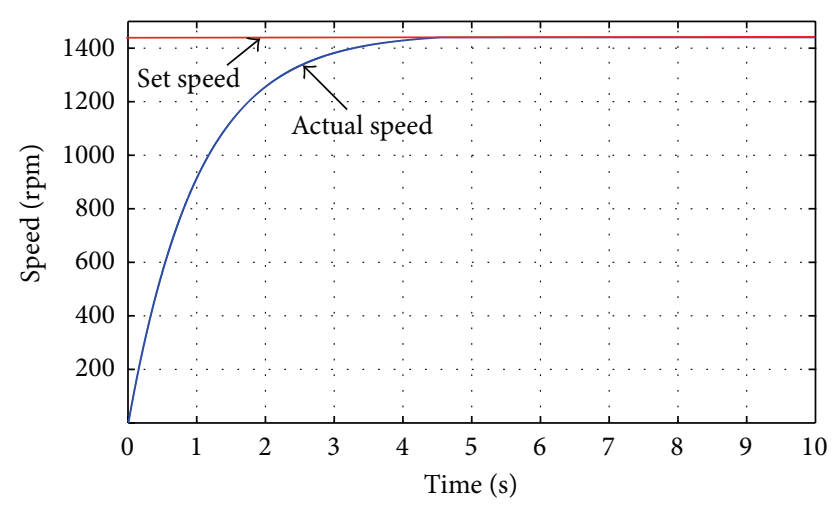

FIGURE 12: Simulated speed response of three-phase IM drive at no load and rated speed.

speed of $3000 \mathrm{rpm}$. The motor attains the set synchronous speed of $3000 \mathrm{rpm}$ in about $280 \mathrm{~ms}$.

5.3. Sensitivity Analysis for Performance Variables of PMSM. Motor parameters like stator resistance and inductance vary depending on operating conditions, mainly motor duty cycle, effect of magnetic saturation, and so forth. The effect of

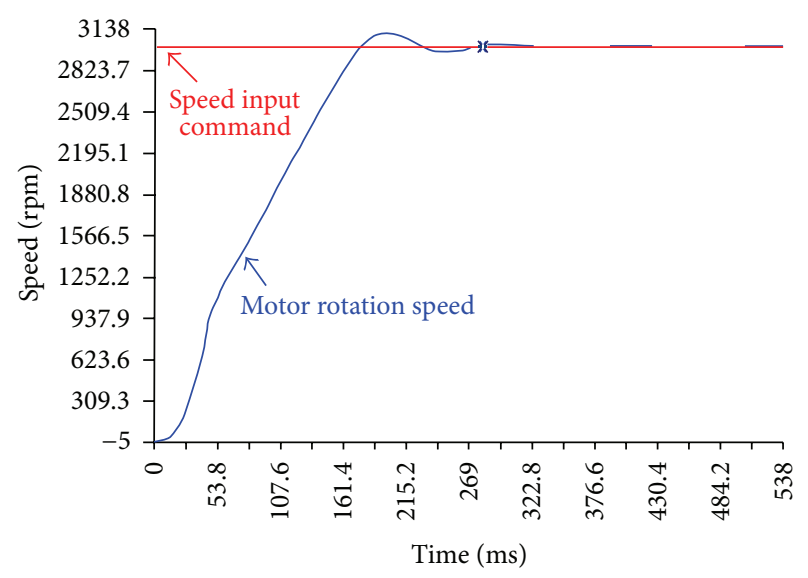

FIGURE 13: Experimental starting response of three-phase PMSM at no load and rated speed.

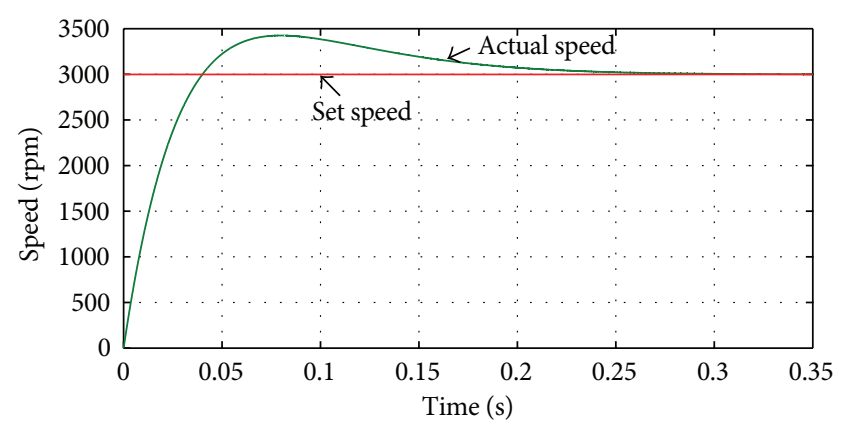

FIGURE 14: Simulated starting response of three-phase PMSM at no load and rated speed.

parametric variations on the efficiency of PMSM has been analyzed and is shown in Figure 15 for rated speed and rated torque conditions, where $\delta$ represents the parameter variation coefficient and is defined as the ratio of new parameter value to the actual parameter value. That is,

$$
\delta=\frac{R_{s}^{\prime}}{R_{s}}=\frac{L_{s}^{\prime}}{L_{s}},
$$

where $R_{s}^{\prime}$ and $L_{s}^{\prime}$ are the new stator resistance and stator inductance, respectively. In the present analysis, $\delta$ is determined for $1 \%$ deviation in motor parameters.

It is observed from Figure 15 that the variation in the efficiency is negligibly small with variation in $R_{s}$ and $L_{s}$, and it follows a Gaussian distribution. The variation in efficiency due to change in $R_{s}$ and $L_{s}$ is expressed as a fourth order polynomial using best fit curve in Figure 15, where

$$
\begin{gathered}
\left.\Delta \eta\right|_{R_{s}}=0.38 \delta^{4}-1.58 \delta^{3}+2.07 \delta^{2}-0.91 \delta+0.04, \\
\left.\Delta \eta\right|_{L_{s}}=0.16 \delta^{4}-0.59 \delta^{3}+0.55 \delta^{2}+0.01 \delta-0.13 .
\end{gathered}
$$

5.4. Sensitivity Analysis for Performance Variables of IM. Table 3 shows the sensitivity of different performance variables of three-phase IM with respect to its equivalent circuit 
TABLE 3: Sensitivity of performance variables of three-phase IM.

\begin{tabular}{lccccccc}
\hline & \multicolumn{7}{c}{ (Output power $=$ full load $=3.7 \mathrm{~kW} . s=0.043)$} \\
Parameters & $R_{s}$ & $R_{r}$ & $X_{s}$ & $X_{r}$ & $X_{m}$ & $V$ & $f$ \\
\hline Power input & -0.022 & -0.891 & -0.099 & -0.014 & 0.035 & 2.010 & -0.078 \\
Power output & -0.107 & -0.888 & -0.103 & -0.021 & 0.085 & 2.090 & -0.037 \\
Efficiency & -0.085 & 0.003 & -0.004 & -0.006 & 0.051 & 0.078 & 0.041 \\
Power factor & 0.029 & -0.235 & -0.050 & -0.038 & 0.289 & 0.000 & 0.202 \\
Stator current & -0.052 & -0.658 & -0.050 & 0.023 & -0.254 & 1.000 & -0.280 \\
Starting current & -0.184 & -0.131 & -0.352 & -0.309 & -0.022 & 1.000 & -0.681 \\
Magnetizing current & -0.052 & 0.063 & -0.050 & -0.004 & -0.950 & 1.000 & -1.003 \\
Torque & -0.103 & -0.854 & -0.099 & -0.020 & 0.082 & 2.010 & -0.036 \\
Starting torque & -0.367 & 0.734 & -0.702 & -0.707 & 0.047 & 2.010 & -1.357 \\
\hline
\end{tabular}

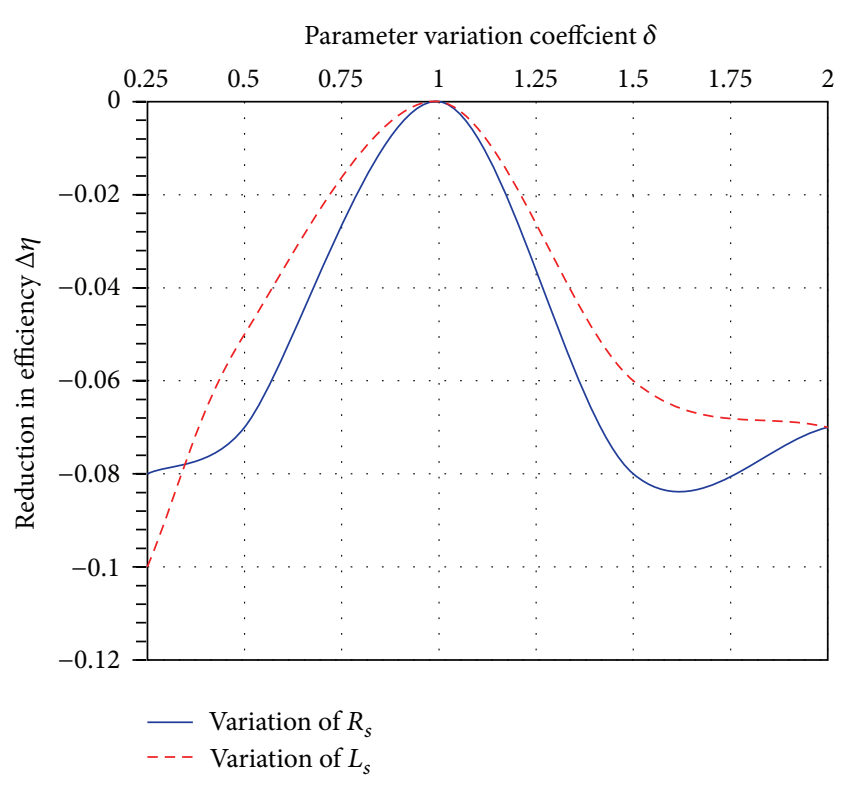

FIGURE 15: Effect of parametric variations on the efficiency of PMSM for rated speed and rated torque.

parameters. The sensitivity of the power input and power output with respect to $R_{r}$ is the highest and is the lowest with respect to $X_{r}$. Motor efficiency is less sensitive to all the equivalent circuit parameters, with variation in $R_{s}$ and $X_{m}$ affecting it more compared to other parameters. The power factor is more affected by variation in $X_{m}$ and $R_{r}$, while variations in other parameters have less effect on it. The stator current is more affected by variation in $R_{r}$ and least by variation in $X_{r}$. The sensitivity of starting current with respect to $X_{s}$ and $X_{r}$ is the highest while with respect to $X_{m}$ is the lowest. Magnetizing current is more sensitive to changes in $X_{m}$ and less sensitive to changes in $X_{r}$. The developed torque and starting torque are mainly affected by variations in $R_{r}$. The sensitivity of developed torque is the least with respect to $X_{r}$ and $X_{m}$, respectively.

The sensitivity of the performance variables with respect to frequency and supply voltage is also obtained. It is observed that the frequency variation has maximum effect on starting torque and magnetizing current followed by starting current. The sensitivity of developed torque with respect to frequency is the least. The sensitivity of power input, power output, developed torque, and starting torque with respect to supply voltage is $2 \%$ each. Similarly, the stator current, starting current, magnetizing current, and so forth change by $1 \%$ with respect to variation in supply voltage. The supply voltage variation has negligible effect on efficiency, while power factor is not affected by supply voltage variation.

\section{Conclusion}

A prototype of distributed drives system, consisting of a three-phase IM drive and a PMSM drive, is designed, developed, and implemented as a laboratory setup. This prototype system demonstrates the operation and control of distributed drives through PLC and SCADA. The operation, control, and monitoring of various performance parameters of PMSM and IM under different operating conditions are carried out in detail. A detailed sensitivity analysis is also carried out to observe the effect of parametric variations on performance of the motors.

\section{Conflict of Interests}

In this research work, GE Fanuc 90-30 Series PLC has been used for creation of the laboratory setup. The said PLC uses Profibus DP protocol for communication between the input/output modules and the drives. The selection of the PLC is intended solely to facilitate research and development work and is not based on any commercial interest.

\section{Acknowledgments}

This work was supported in part by the MODROB Scheme of AICTE, India. The authors gratefully acknowledge the support provided by AICTE, India, and GE Fanuc in setting up the laboratory infrastructure in the Electrical Engineering Department at Delhi Technological University, New Delhi, India. 


\section{References}

[1] J. Chang, "High-frequency and precision three-phase sine/ PWM controller with near-zero frequency of MPU intervention-novel design supporting distributed AC drive systems," IEEE Transactions on Industrial Electronics, vol. 52, no. 5, pp. 1286-1296, 2005.

[2] J. M. Liptak, H. R. Orndorff, and E. M. Innes, "A programmable local controller for AC adjustable frequency drive controllers," in Proceedings of the IEEE Industry Applications Society Annual Meeting, vol. 1, pp. 572-577, October 1988.

[3] M. G. Ioannides, "Design and implementation of PLC-based monitoring control system for induction motor," IEEE Transactions on Energy Conversion, vol. 19, no. 3, pp. 469-476, 2004.

[4] Y. Birbir and H. S. Nogay, "Design and implementation of PLCbased monitoring control system for three phase induction motors fed by PWM inverter," International Journal of Systems Applications, Engineering and Development, vol. 2, no. 3, pp. 128-135, 2008.

[5] A. R. Al-Ali, M. M. Negm, and M. Kassas, "A PLC based power factor controller for a 3-phase induction motor," in Proceedings of the IEEE Industry Applications Society Annual Meeting (IAS '00), vol. 2, pp. 1065-1072, October 2000.

[6] J. Y. Jyang and Y. Y. Tzou, "A CPLD based voltage/current vector controller for 3- phase PWM inverters," in Proceedings of the 29th Annual IEEE Power Electronics Specialists Conference, vol. 1, pp. 262-268.

[7] M. S. Thomas, P. Kumar, and V. K. Chandna, "Design, development, and commissioning of a supervisory control and data acquisition (SCADA) laboratory for research and training," IEEE Transactions on Power Systems, vol. 19, no. 3, pp. 15821588, 2004.

[8] R. D. Pedroza, Internet based FLARE and LFGTE facilities Remote Monitoring and Control, http//www.scsengineers.com/ Papers/Pedroza_Internet_Based_Flare_and_LFGTE_SWANA 2007.pdf.

[9] R. Krishnan and F. C. Doran, "Study of parameter sensitivity in high performance inverter fed Induction motor Drive systems," IEEE Transactions on Industry Applications, vol. 23, no. 4, pp. 623-635, 1987.

[10] S. B. Bodkhe and M. V. Aware, "Speed-sensorless, adjustablespeed induction motor drive based on dc link measurement," International Journal of Physical Sciences, vol. 4, no. 4, pp. 221232, 2009.

[11] J. Holtz, "Sensorless control of induction motor drives," Proceedings of the IEEE, vol. 90, no. 8, pp. 1359-1394, 2002.

[12] K. Rajashekara, A. Kawamura, and K. Matsuse, Eds., Sensorless Control of AC Drives, IEEE Press, New York, NY, USA, 1996.

[13] B. K. Bose and N. R. Patel, "Sensorless stator flux oriented vector controlled induction motor drive with neuro-fuzzy based performance enhancement," in Proceedings of the 32nd IEEE Industry Applications Conference IAS Annual Meeting, pp. 393400, October 1997.

[14] C. Schauder, "Adaptive speed identification for vector control of induction motors without rotational transducers," IEEE Transactions on Industry Applications, vol. 28, no. 5, pp. 10541061, 1992.

[15] R. C. Garcìa, W. I. Suemitsu, and J. O. P. Pinto, "Precise position control of a PMSM based on new adaptive PID controllers," in Proceedings of Annual Conference of the IEEE Industrial Electronics Society, pp. 1912-1917, November 2011.
[16] M. Tárník and J. Murgaš, "Model reference Adaptive control of permanent magnet synchronous motor," Journal of Electrical Engineering, vol. 62, no. 3, pp. 117-125, 2011.

[17] P. Pillay and R. Krishnan, "Modeling, simulation, and analysis of permanent-magnet motor drives. I. The permanent-magnet synchronous motor drive," IEEE Transactions on Industry Applications, vol. v, pp. 265-273, 1989.

[18] S. Vaez-Zadeh, "Variable flux control of permanent magnet synchronous motor drives for constant torque operation," IEEE Transactions on Power Electronics, vol. 16, no. 4, pp. 527-534, 2001.

[19] Z. Haigang, Q. Weiguo, W. Yanxiang, G. Shihong, and Y. Yuan, "Modeling and simulation of the permanent magnet synchronous motor drive," in Proceedings of the International Conference on Uncertainty Reasoning and Knowledge Engineering Energy, pp. 256-260, 2011.

[20] B. K. Bose, Modern Power Electronics and AC Drives, Pearson Education, Upper Saddle River, NJ, USA, 1st edition, 2003.

[21] R. Krishnan, Electric Motor Drives- Modeling Analysis and Control, Pearson Prentice Hall, Upper Saddle River, NJ, USA, 1st edition, 2007.

[22] Proficy Machine Edition 5. 90 User's Manual, GE Fanuc, Yamanashi, Japan, 2007.

[23] "Versa Motion Servo Motors and Amplifiers User's Manual," Tech. Rep. GFK-2480, GE Fanuc, Yamanashi, Japan, 2007. 

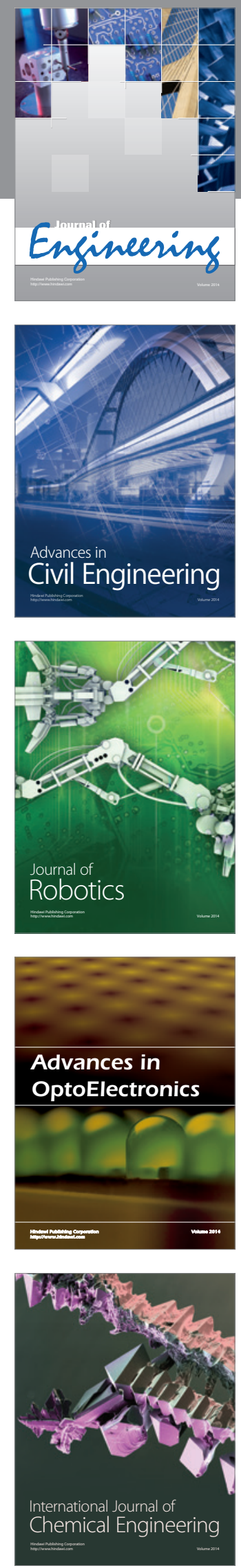

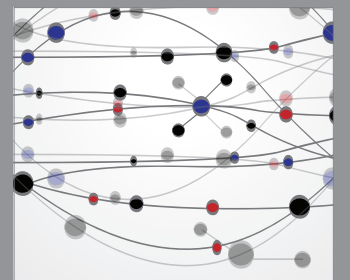

The Scientific World Journal
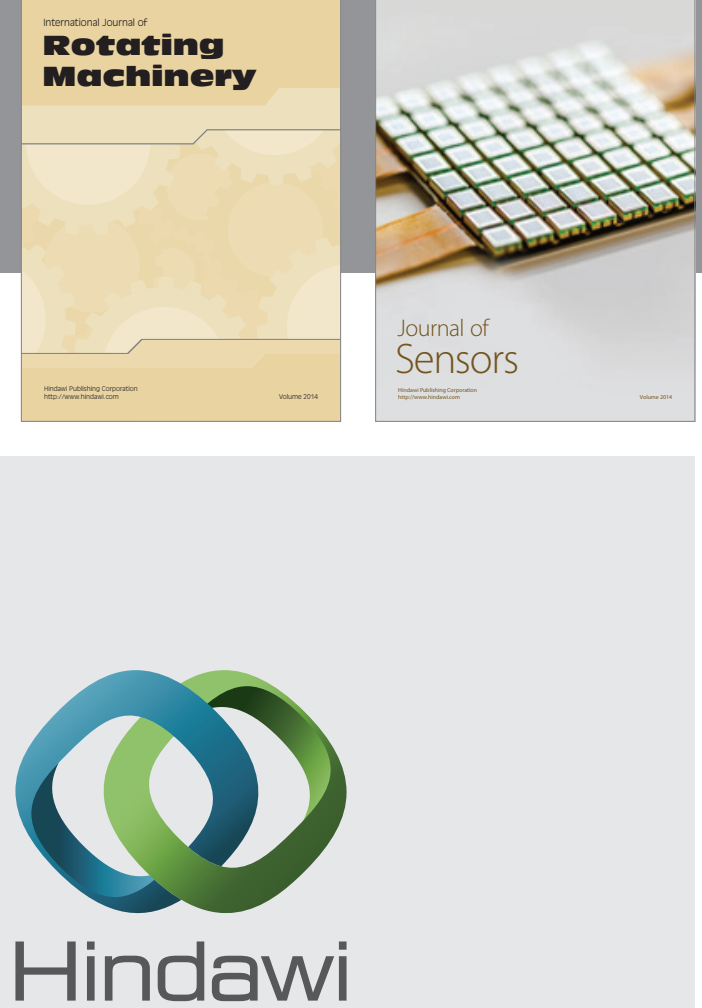

Submit your manuscripts at http://www.hindawi.com
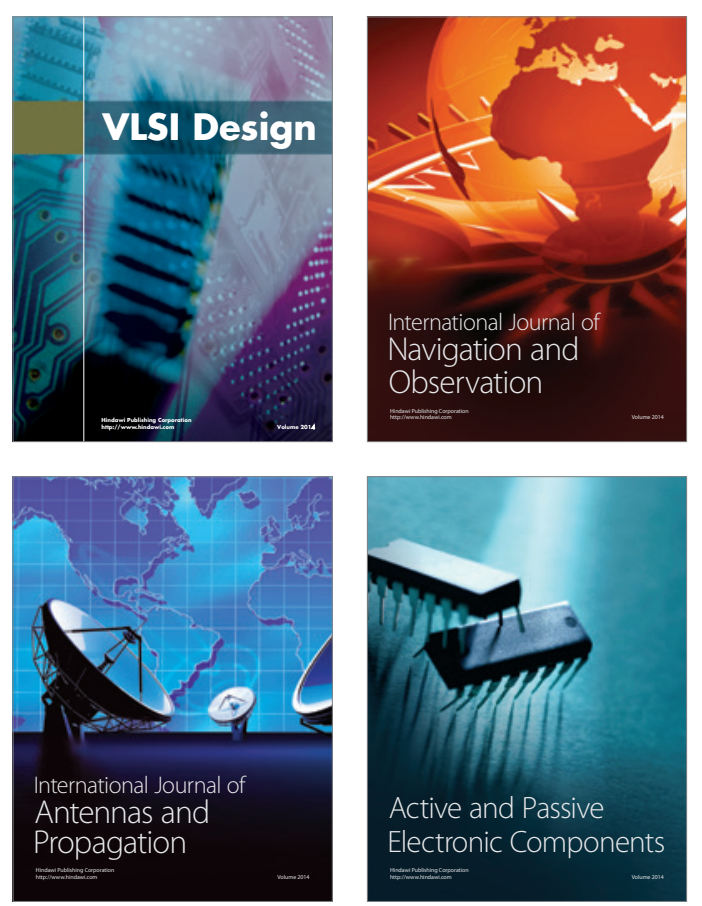
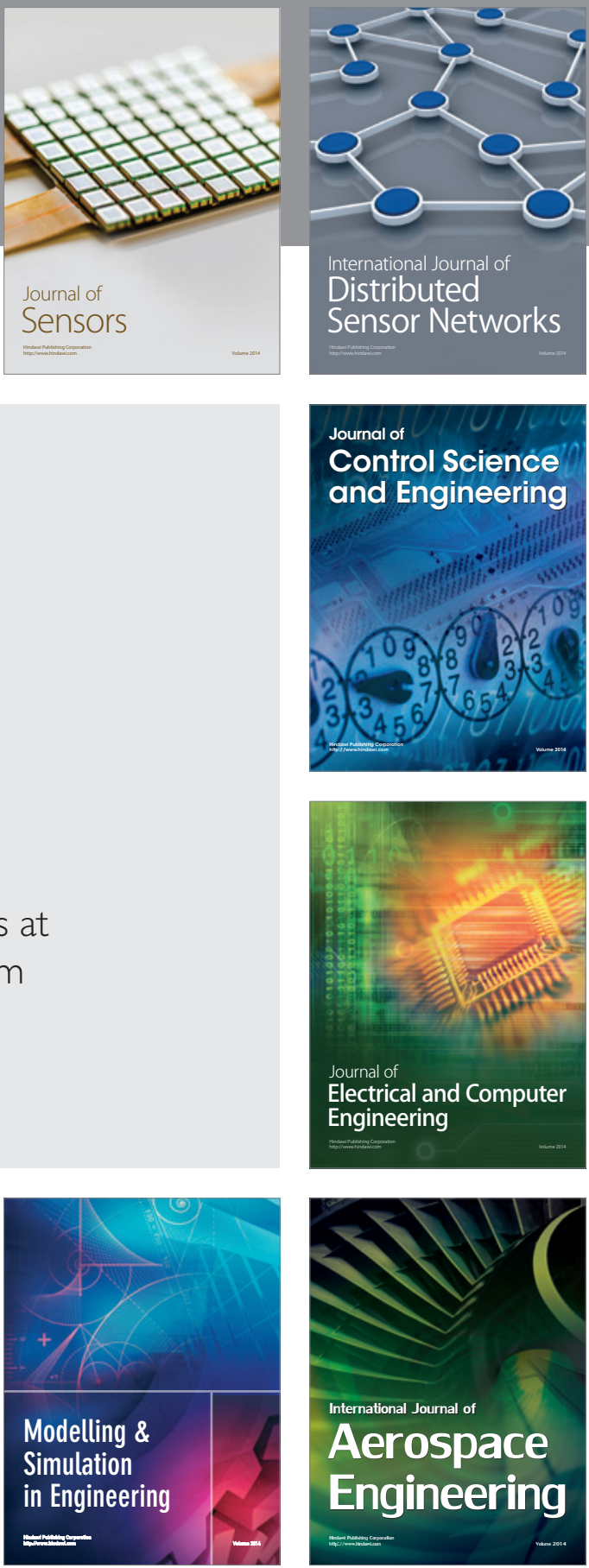

Journal of

Control Science

and Engineering
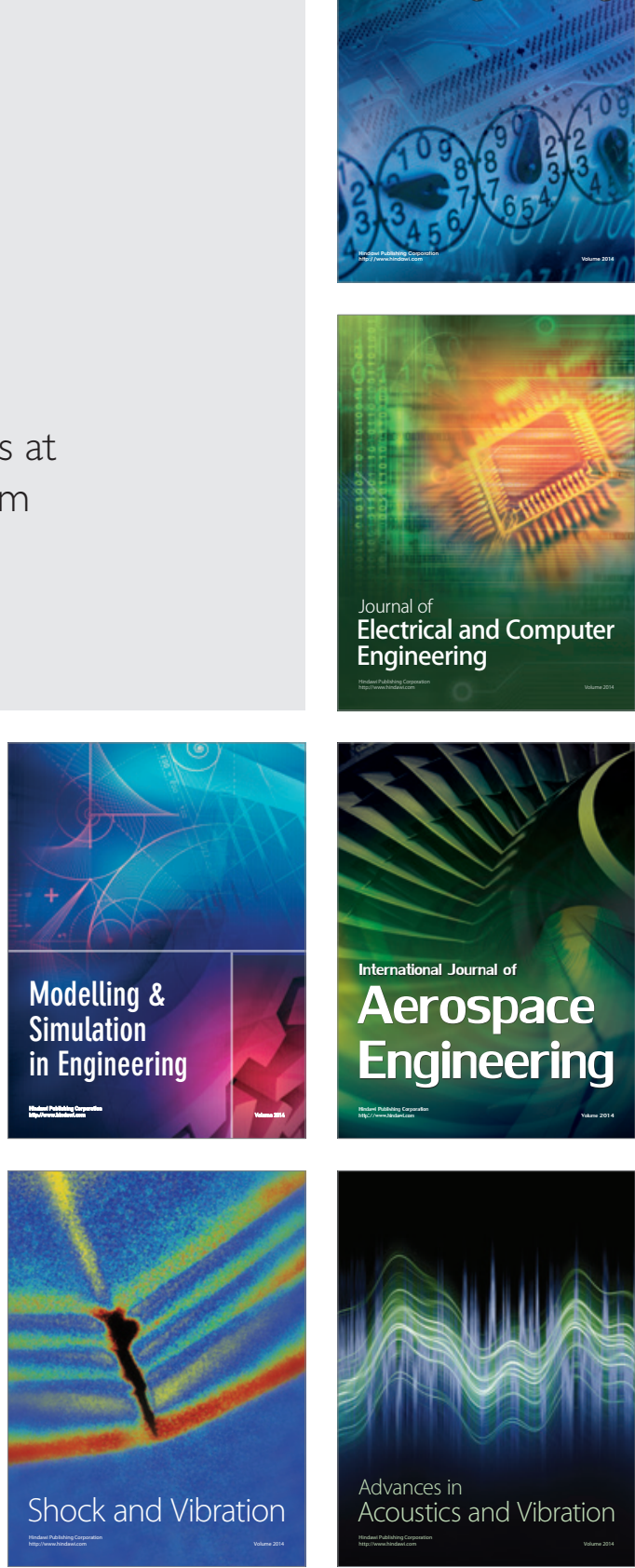